\title{
Assessment of physicians' knowledge and awareness about the hazards of radiological examinations on the health of their patients
}

A. Hamarsheh ${ }^{7}$ and M. Ahmead ${ }^{2}$

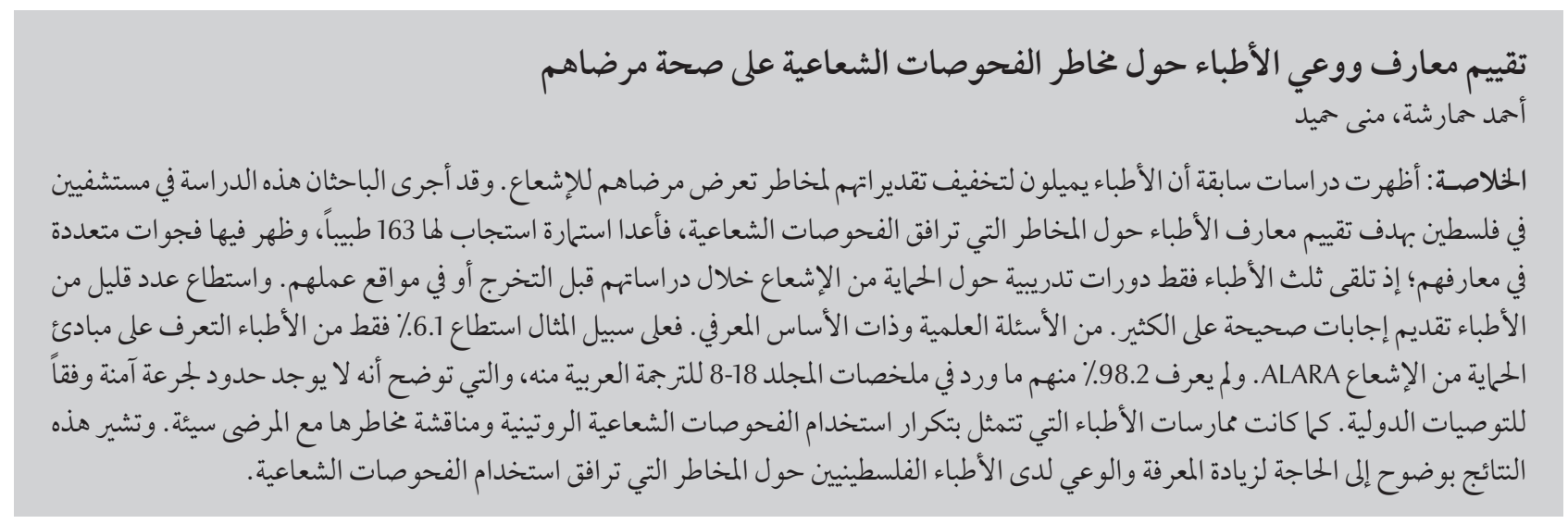

ABSTRACT Previous studies have shown that physicians tend to underestimate the risks to patients of radiation exposure. This study in 2 Palestinian hospitals aimed to assess physicians' knowledge about the risks associated with the use of radiological examinations. A questionnaire answered by 163 physicians revealed many gaps in knowledge. Only one-third of physicians had received a radiation protection course during their undergraduate study or in the workplace. Few physicians were able to answer correctly many scientific, knowledge-based questions. For example, only $6.1 \%$ of the respondents were able to identify the ALARA principle and $98.2 \%$ did not know that there is no safe dose limit according to international recommendations. Physicians' practices in terms of frequency of use of routine X-rays and discussing the risks with patients were also poor. These results clearly indicate the need to increase Palestinian physicians' knowledge and awareness about the potential hazards associated with the use of radiological examinations.

Évaluation des connaissances et de la sensibilisation des médecins sur les dangers des examens radiologiques pour la santé de leurs patients

RÉSUMÉ Des études antérieures ont démontré que les médecins avaient tendance à sous-estimer les risques de l'exposition radiologique pour leurs patients. La présente étude menée dans deux hôpitaux palestiniens visait à évaluer les connaissances des médecins en termes de risques associés à l'utilisation des examens radiologiques. Un questionnaire rempli par 163 médecins a révélé de nombreuses lacunes. Seul un tiers des médecins avaient suivi une formation sur la protection radiologique au cours de leur premier cycle d'études ou sur leur lieu de travail. Les médecins qui étaient capables de répondre correctement aux nombreuses questions scientifiques de base étaient peu nombreux. Par exemple, seuls 6,1\% des répondants étaient capables de décrire le principe ALARA et 98,2 \% ignoraient qu'il n'existait pas de seuil en dessous duquel une dose est sans danger, selon les recommandations internationales. Les pratiques des médecins en termes de fréquence d'utilisation des examens radiologiques routiniers et de discussion sur les risques avec leurs patients étaient aussi médiocres. Ces résultats pointent clairement la nécessité d'augmenter le niveau de connaissances et de sensibilisation des médecins palestiniens au sujet des dangers potentiels associés aux examens radiologiques. 


\section{Introduction}

Nowadays, medical imaging procedures involving the use of ionizing radiation are used daily in hospitals and clinics, making possible more accurate diagnosis of diseases and injuries. However, the use of ionizing radiation such as $\mathrm{X}$ rays is also associated with potentially harmful biological effects. Specifically, high radiation doses tend to kill cells, while low doses tend to damage or alter the DNA of irradiated cells $[1,2]$. In recent times, many studies have clearly documented the harmful effects of radiological examinations [3-7]. Brenner estimated that of 600000 children given abdominal and head computed tomography (CT) examinations annually in the United States of America (USA), 500 might ultimately die from cancer attributable to the radiation [3]. In the United Kingdom (UK) an estimated 250 people die annually as a result of cancer secondary to medical radiation exposure [6]. Yet many studies indicate that primary care providers are unaware of the hazards associated with the use of radiation. Physicians who are responsible for requesting radiological examinations tend to underestimate the actual doses involved, have poor knowledge about the possible risks to the health of populations and do not discuss the potential risks of $\mathrm{CT}$ scans with their patients [8-15].

In the West Bank, 2 universities have medical schools that offer a 6-year baccalaureate degree in medicine. However, neither of these offers a radiology course for their students during their undergraduate studies. This is striking, since, after graduation, these physicians will be the only health professionals having the authority to request radiological examinations. In addition, the literature reveals a lack of studies in Palestine about the hazards of unnecessary use of radiological examinations. The aim of this study was to assess the knowledge and awareness of Palestinian physicians regarding the hazards of utilizing radiological examinations with patients in their clinical practice.

\section{Methods}

\section{Target population and setting}

A cross-sectional study design was utilized. The participants of the study were physicians who were recruited from the 2 largest referral hospitals in Palestine: Al-Makassed hospital (250 beds), located on the Mount of Olives in Jerusalem and offering both inpatient and outpatient services in most medical specialties, and Ramalla government hospital (150 beds), located in the centre of Ramalla city. Both of them are fully accredited for postgraduate training in 6 medical specialties, including internal medicine, surgery, paediatrics, gynaecology, and orthopaedics, by both the Jordanian and the Palestinian Medical Councils. Annually these 2 hospitals together treat more than 150000 people. There were 107 physicians working in Al-Makassed hospital and 60 physicians in Ramalla government hospital.

\section{Instrument}

The measurement tool was a self-reported questionnaire which was developed from 5 previous published studies $[9,10,13,16,17]$. The questionnaire consisted of 2 sections: section 1 requested information about sociodemographic variables such as workplace, sex, occupation, specialty, country of medical graduation and years of clinical practice, while section 2 consisted of items related to the physicians' knowledge of radiation hazards. (The questionnaire is available on request from the first author.)

The validity of the instrument was checked by a committee of 9 physicians and 4 other experts in medicine and radiation, who reviewed the content, the clarity and the relevance of the items. The questionnaire was written in the English language in response to the committee's request, since English is the normal language for these physicians in their everyday clinical practice.

\section{Data collection and analysis}

The administrations of the 2 hospitals were approached and gave permission for the authors to conduct the study. The questionnaires were individually hand delivered to the physicians in each setting, accompanied by an information sheet explaining the purpose of the study. This sheet endorsed the right of the participants not to participate, and that their consent to participate was implied by the return of the questionnaire. The data collection was from June 2008 to November 2009. Most of the questionnaires were collected during the first days of data collection in both hospitals, while physicians who were on leave filled in the questionnaires after their return to work.

The data was managed and analysed by using SPSS, version 15 . The characteristics of the participants were obtained through descriptive analysis using frequencies and percentages

\section{Results}

\section{Background characteristics}

Out of the 167 physicians, 163 returned the completed questionnaire, thus the response rate was high (97.6\%). As shown in Table 1, the great majority of the respondents were males (85.3\%). Also $43.6 \%$ were consultants, $47.9 \%$ were residents engaged in medical qualification programmes under consultant supervision and $8.6 \%$ belonged to other medical practice categories. The largest specialty groups of respondents were internal medicine specialists (19.6\%) and surgeons (18.4\%).

Less than half of the respondents (43.6\%) graduated from medical programmes in Arab countries such as Palestine, Jordan and Egypt, 19.6\% graduated from former Soviet Union countries, 12.3\% from Europe and the 


\begin{tabular}{|c|c|c|}
\hline \multicolumn{3}{|c|}{$\begin{array}{l}\text { Table } 1 \text { Background characteristics of the participating physicians from } 2 \\
\text { Palestinian hospitals }(n=163)\end{array}$} \\
\hline Item & No. & $\%$ \\
\hline \multicolumn{3}{|l|}{ Workplace } \\
\hline Al Makassed hospital & 103 & 63.2 \\
\hline Ramalla government hospital & 60 & 36.8 \\
\hline \multicolumn{3}{|l|}{ Sex } \\
\hline Male & 139 & 85.3 \\
\hline Female & 24 & 14.7 \\
\hline \multicolumn{3}{|l|}{ Occupation } \\
\hline Consultant & 71 & 43.6 \\
\hline Resident & 78 & 47.9 \\
\hline Other & 14 & 8.6 \\
\hline \multicolumn{3}{|l|}{ Specialty } \\
\hline Surgery & 30 & 18.4 \\
\hline Medicine & 32 & 19.6 \\
\hline Paediatrics & 22 & 13.5 \\
\hline Gynaecology & 14 & 8.6 \\
\hline Orthopaedics & 14 & 8.6 \\
\hline Anaesthesia & 13 & 8.0 \\
\hline Emergency & 9 & 5.5 \\
\hline Data missing & 29 & 17.8 \\
\hline \multicolumn{3}{|l|}{ Country of medical graduation } \\
\hline European country/United States & 20 & 12.3 \\
\hline Arab country & 71 & 43.6 \\
\hline Former Soviet Union country & 32 & 19.6 \\
\hline Other & 8 & 4.9 \\
\hline Data missing & 32 & 19.6 \\
\hline \multicolumn{3}{|l|}{ Years of clinical practice } \\
\hline$<5$ & 57 & 35.0 \\
\hline $5-10$ & 52 & 31.9 \\
\hline $11-20$ & 23 & 14.1 \\
\hline$>20$ & 31 & 19.0 \\
\hline
\end{tabular}

United States. The work experience of the respondents ranged from $<5$ years to $>20$ years, with more than one-third of the participants $(35.0 \%)$ indicating work experience of $<5$ years.

The participants were asked if they had attended any radiation protection courses, either during their medical studies or in their workplace. Interestingly, 115 (70.6\%) of the respondents indicated that they had not attended a radiation protection course during their studies, and only 50 (30.7\%) indicated that they had received such a course at their workplaces.
CT scans, especially among children, and only $54.6 \%$ knew that the Food and Drug Administration (FDA) in the USA has listed medical X-rays as a known carcinogen.

To further test their level of knowledge, respondents were asked to select which type of device delivers a higher radiation dose to the patient: single-slice helical scanners or multi-slice CT scanners; only $13.5 \%$ selected the correct answer, the multi-slice CT scanner. When asked about the percentage of total ionizing radiation the general public is exposed to which comes from "medical radiation", only $8.0 \%$ of the respondents knew that it constitutes $15 \%-30 \%$ of radiation, while the majority of respondents (63.2\%) did not know. Furthermore, the respondents were asked about the whole-body dose limit for a patient, which has been established by radiation protection regulations; and only $1.8 \%$ of the respondents indicated correctly that there is in fact no dose limit defined for patients, while the majority ( $81.0 \%)$ indicated that they did not know. Regarding the International Commission on Radiological Protection (ICRP) recommendations defining professional responsibility for protecting patients from unnecessary radiation doses, onethird of the respondents (31.9\%) knew that these recommendations forbid unjustified exposure to ionizing radiation and place responsibility for protecting patients from unnecessary radiation doses on both the prescriber and the practitioner; more than half of respondents $(57.7 \%)$ did not know the answer.

To assess their knowledge in more depth, the respondents were asked to rank the radiation sensitivity of each of 5 bodily organs from 1 (lowest) to 4 (highest). Table 3 shows that less than half of the respondents (44.8\%) knew that the gonads were the most radiosensitive organ, only $19.6 \%$ identified the lungs as the second most radiosensitive and few of them (5.5\%) were able to select the stomach as the second most radiosensitive organ. 


\begin{tabular}{|c|c|c|}
\hline Item & No. & $\%$ \\
\hline \multicolumn{3}{|l|}{ Aware of ALARA principle } \\
\hline Yes & 153 & 93.9 \\
\hline No & 10 & 6.1 \\
\hline \multicolumn{3}{|c|}{ Know any published articles on radiation hazards } \\
\hline Yes & 75 & 46.0 \\
\hline No & 88 & 54.0 \\
\hline \multicolumn{3}{|l|}{$\begin{array}{l}\text { Know about FDA listing medical } X \text {-rays as } \\
\text { a known carcinogen }\end{array}$} \\
\hline Yes & 89 & 54.6 \\
\hline No & 74 & 45.4 \\
\hline \multicolumn{3}{|l|}{$\begin{array}{l}\text { Think radiation dose to patient from multi-slice } \\
\text { CT scanner is: }\end{array}$} \\
\hline Higher than single-slice helical scanner ${ }^{a}$ & 22 & 13.5 \\
\hline Lower than single-slice helical scanner & 36 & 22.1 \\
\hline Similar to single-slice helical scanner & 11 & 6.7 \\
\hline Don't know & 94 & 57.7 \\
\hline \multicolumn{3}{|l|}{$\begin{array}{l}\text { \% of total ionizing radiation the general public is } \\
\text { exposed to from medical radiation }\end{array}$} \\
\hline $1-10$ & 21 & 12.9 \\
\hline $15-30^{\text {a }}$ & 13 & 8.0 \\
\hline $35-45$ & 11 & 6.7 \\
\hline $60-75$ & 9 & 5.5 \\
\hline $80-95$ & 6 & 3.7 \\
\hline Don't know & 103 & 63.2 \\
\hline \multicolumn{3}{|l|}{$\begin{array}{l}\text { Recommended patient dose limit for medical } \\
\text { radiation (msv) }\end{array}$} \\
\hline 100 & 5 & 3.1 \\
\hline 50 & 7 & 4.2 \\
\hline 20 & 5 & 3.1 \\
\hline 5 & 6 & 3.7 \\
\hline 0.5 & 5 & 3.1 \\
\hline No dose limit ${ }^{\mathrm{a}}$ & 3 & 1.8 \\
\hline Don't know & 132 & 81.0 \\
\hline \multicolumn{3}{|c|}{$\begin{array}{l}\text { ICRP recommendations for professional responsibility for } \\
\text { protecting patients }\end{array}$} \\
\hline According to the freedom of prescription & 2 & 1.2 \\
\hline Prescriber, not practitioner & 5 & 3.1 \\
\hline Practitioner, not prescriber & 10 & 6.1 \\
\hline Both prescriber and practitioner ${ }^{\mathrm{a}}$ & 52 & 31.9 \\
\hline Don't know & 94 & 57.7 \\
\hline
\end{tabular}

${ }^{a}$ Correct answer.

$A L A R A=$ As Low As Reasonably Achievable $F D A=$ Food and Drug Administration; $C T=$ computerized tomography; ICRP = International Commission on Radiological Protection.

Another aspect of the physicians' knowledge examined was their estimation of the effective doses of selected radiological examinations, including lumbar spine, abdominal CT scan and barium enema, expressed in terms of units equivalent to a single frontal posterior anterior chest X-ray (Table 4).
Only $4.3 \%$ of the participants knew that the radiation dose from 1 lumbar spine exam is equal to that from 65 posterior anterior chest X-rays; $8.6 \%$ knew that the radiation dose from 1 abdominal CT scan is equal to that from more than 250 chest X-rays; and $3.1 \%$ indicated correctly that the radiation dose from 1 barium enema is likewise equal to that from over 250 chest $X$-rays.

\section{Radiation practices}

When the respondents were asked how often they requested routine Xray examinations and $\mathrm{CT}$ scans for the diagnosis of their patients, $74.3 \%$ indicated that they requested routine $\mathrm{X}$-ray examinations sometimes or often and $58.3 \%$ requested CT scans sometimes or often, while $40.5 \%$ rarely requested CT scans (Table 5).

Despite the physicians' frequent requests for these radiological examinations, more than half of them (55.2\%) reported that they did not outline all the attendant risks and benefits of X-ray examinations to their patients or their families prior to conducting these examinations, while $44.8 \%$ reported that they did so. Participants were asked if the patients and their families requested information about the radiation doses and risks before consenting to undergoing radiological examinations. More than one-third of the respondents (38.7\%) indicated that it happened rarely (approximately 1 in 100 patients).

Participants were asked about their intention to reduce their requests for various types of radiological examinations, including routine $\mathrm{X}$-ray exams, CT scans and fluoroscopy if there were a proven increase in lifetime risk of cancer associated with these procedures (Table 6). The majority of respondents $(61.4 \%)$ indicated that they would do so in the case of routine $\mathrm{X}$-ray examinations, whereas 38.6\% indicated that they would not. A majority (69.9\%) reported that they would reduce their requests for CT scans. 


\begin{tabular}{|c|c|c|c|c|c|c|c|c|c|c|}
\hline \multirow[t]{2}{*}{ Estimated sensitivity levela } & \multicolumn{2}{|c|}{ Lungs } & \multicolumn{2}{|c|}{ Bladder } & \multicolumn{2}{|c|}{ Gonads } & \multicolumn{2}{|c|}{ Kidneys } & \multicolumn{2}{|c|}{ Stomach } \\
\hline & No. & $\%$ & No. & $\%$ & No. & $\%$ & No. & $\%$ & No. & $\%$ \\
\hline 1 & 15 & 9.2 & 6 & 3.7 & 73 & 44.8 & 4 & 2.5 & 10 & 6.1 \\
\hline 2 & 32 & 19.6 & 25 & 15.3 & 6 & 3.7 & 16 & 9.8 & 9 & 5.5 \\
\hline 3 & 17 & 10.4 & 23 & 14.1 & 3 & 1.8 & 32 & 19.6 & 15 & 9.2 \\
\hline 4 & 18 & 11.0 & 28 & 17.2 & 9 & 5.5 & 27 & 16.6 & 35 & 21.5 \\
\hline Don't know & 75 & 46.0 & 73 & 44.8 & 72 & 44.2 & 77 & 47.2 & 81 & 49.7 \\
\hline Missing data & 6 & 3.7 & 8 & 4.9 & 0 & 0.0 & 7 & 4.3 & 13 & 8.0 \\
\hline Total & 163 & 100.0 & 163 & 100.0 & 163 & 100.0 & 163 & 100.0 & 163 & 100.0 \\
\hline
\end{tabular}

aParticipants rank the radiation sensitivity of organs from 1 (lowest) to 4 (highest).

\section{Discussion}

In general, the results of the current study in Palestine are similar to the findings of previous studies in the literature and indicate a similar lack of knowledge among physicians regarding the possible risks of radiological examinations $[6,11,14,15,18]$

This lack of knowledge of radiological issues was certainly evident, with only $6.1 \%$ of our Palestinian physicians able to identify the ALARA principle, even though this principle comprises the core of radiation protection philosophy [19]. This percentage is in fact considerably lower than those found from other studies, which ranged from $15 \%$ to $48 \%[10,13]$. Many diagnostic ionizing procedures that are performed every day can potentially expose both patients and the medical staff to high levels of radiation, and this may cause negative health effects on the human body [20]. Our findings showed that the great majority of the respondents (98.2\%) did not know that patients have no defined safe dose limit according to ICRP guidelines, and this percentage is higher than that reported by Quinn et al. $(70 \%)$ [10].

Furthermore, physicians should have the ability to compare the radiation doses that are associated with the various medical imaging modalities and to express the effective doses in terms of chest X-ray equivalent units. This not only has proven useful in previous physician-based studies but is important in helping patients and their families to understand the relative risks $[6,10,11]$. On average, only $5 \%$ of the participants were able to identify the effective dose equivalent compared to a chest X-ray of a routine lumbar spine
X-ray examination, a barium enema and an abdominal and pelvic CT scan. The literature indicates similar results from other studies that on average fewer than $6 \%$ of physicians were able to distinguish these relative doses $[8,9,16]$.

Physicians' knowledge of the public's overall exposure to ionizing radiation is another important aspect of their clinical practice. Only $8 \%$ of the participants knew that medical radiation accounts for $15 \%$ to $30 \%$ of the general public's total exposure to ionizing radiation from all sources, which include radon, gamma rays and cosmic radiation. Also, only $9.2 \%$ of our respondents were able to estimate the increased cancer risk from radiation exposure connected with an abdominal and pelvic $\mathrm{CT}$ scan $(1: 1000)$. This result is similar to the $6 \%$ found in another study [13], but inconsistent with the $31 \%$ reported in Rice's study [9]. This difference could be due

\begin{tabular}{|c|c|c|c|c|c|c|}
\hline \multirow{2}{*}{ No. of chest X-ray equivalents } & \multicolumn{2}{|c|}{ Lumbar spine X-ray } & \multicolumn{2}{|c|}{ Abdominal CT scan } & \multicolumn{2}{|c|}{ Barium enema } \\
\hline & No. & $\%$ & No. & $\%$ & No. & $\%$ \\
\hline$<1$ & 6 & 3.7 & 7 & 4.3 & 6 & 3.7 \\
\hline 10 & 24 & 14.7 & 6 & 3.7 & 10 & 6.1 \\
\hline $65^{\mathrm{a}}$ & 7 & 4.3 & 15 & 9.2 & 14 & 8.6 \\
\hline 120 & 0 & 0.0 & 7 & 4.3 & 9 & 5.5 \\
\hline 250 & 0 & 0.0 & 7 & 4.3 & 2 & 1.2 \\
\hline$>250$ & 2 & 1.2 & 14 & 8.6 & 5 & 3.1 \\
\hline Don't know & 124 & 76.1 & 107 & 65.6 & 117 & 71.8 \\
\hline Total & 163 & 100.0 & 163 & 100.0 & 163 & 100.0 \\
\hline
\end{tabular}

${ }^{a}$ Correct answer.

$C T=$ computerized tomography. 


\begin{tabular}{lrrrr}
\hline \multicolumn{2}{l}{ Table 5 Physicians' reported frequency of requests for examinations } & & & CT scan \\
\hline Frequency of requests & No. & Routine X-ray & & No. \\
& 2 & 1.2 & 2 & 1.2 \\
Never & 40 & 24.5 & 66 & 40.5 \\
Rarely (< 25\% of the time) & 64 & 39.3 & 73 & 44.8 \\
Sometimes (25\%-75\% of the time) & 57 & 35.0 & 22 & 13.5 \\
Often (> 75\% of the time) & 163 & 100.0 & 163 & 100.0 \\
Total & & & & $\%$ \\
\hline
\end{tabular}

$C T=$ computerized tomography.

to the recent focus in the media in the USA and other developed countries on the risks of over-requesting CT scans, as well as to increased concern among medical faculties about radiation issues [9].

On other hand, a fairly high percentage of our participants (46.0\%) indicated that they had read articles published in scientific or professional journals or in the general media regarding radiation hazards, such as cancers that have been associated with CT scans; this result is similar to the $48 \%$ found by another study [13]. However, our respondents' answers to the specific scientific questions posed were not consistent with this positive finding, as discussed previously. Also, considering that these 2 hospitals are the largest referral hospitals in Palestine, and both offer 4-year clinical training programmes leading to specialty certification in various fields, this percentage is lower than expected. It is known that physicians at Palestinian hospitals have difficulty accessing scientific journals and the related electronic databases and therefore greater access should be offered to these physicians in order to increase their knowledge and awareness regarding the radiation hazards of radiological examinations.

The results of the study raise a relevant question: If these physicians are aware of the known carcinogenic effects of radiological examination as they reported, why did they not reduce their requests for these examinations in order to protect their patients, recalling that the majority indicated that they request such examinations often, i.e. more than $75 \%$ of the time. This is a much higher level than that found in similar previous research (32\%) [11]. These findings would seem to support those of the ICRP reports, which indicated that many radiological examinations worldwide are ordered without adequate justification [21].

Our results showed that less than one-third of the physicians had participated in a radiation protection course during their undergraduate study or at their workplace (29.4\% and 30.7\% respectively). This situation suggests the need to design and conduct such courses or training workshops, both within the medical schools and in hospital workplaces, taking into consideration the frequent changes in the available biological and physical information and radiation safety standards [21].

The limitations of the study include the use of a self-reported questionnaire, making it difficult to validate the accuracy of the findings since some participants may exaggerate their knowledge. Also, this study involved only the 2 largest referral hospitals in Palestine, thus the generalization of the findings to other health settings may be limited. Further research is required to assess the level of radiological knowledge among medical students in their final year of medical studies and among other health professionals, such as radiological technologists. Finally, further qualitative study would be helpful in exploring in depth the factors contributing to physicians' lack of knowledge, as well as the physicians' actual practices.

\section{Acknowledgements}

Mygratitudegoesto DrAdnan Al-Laham, for his sustained support, encouragement and assistance and all the physicians their participation and cooperation, which helped make this study a reality.

\begin{tabular}{|c|c|c|c|c|c|c|}
\hline \multirow{2}{*}{$\begin{array}{l}\text { Will reduce use of } \\
\text { method }\end{array}$} & \multicolumn{2}{|c|}{ Routine X-ray } & \multicolumn{2}{|c|}{ Fluoroscopy } & \multicolumn{2}{|c|}{ CT scan } \\
\hline & No. & $\%$ & No. & $\%$ & No. & $\%$ \\
\hline Yes & 100 & 61.3 & 98 & 60.1 & 114 & 69.9 \\
\hline No & 63 & 38.7 & 65 & 39.9 & 49 & 30.1 \\
\hline Total & 163 & 100.0 & 163 & 100.0 & 163 & 100.0 \\
\hline
\end{tabular}

$C T=$ computerized tomography. 


\section{References}

1. Stein JJ. The carcinogenic hazards of ionizing radiation in diagnostic and therapeutic radiology. CA: a Cancer Journal for Clinicians, 1967, 17:278-287.

2. Scanff $\mathrm{P}$ et al. Population exposure to ionizing radiation from medical examinations in France. British Journal of Radiology, 2008, 81:204-213.

3. Brenner DJ. Fractionation and late rectal toxicology. International Journal of Radiation Oncology, 2004, 60:1013-1015.

4. Wang JX et al. Cancer incidence and risk estimation among medical X-ray workers in China, 1950-1995. Health Physics, 2002, 82:455-466.

5. Goldberg Z et al. Effects of low-dose ionizing radiation on gene expression in human skin biopsies. International Journal of Radiation Oncology, Biology, Physics, 2004, 58:567-574.

6. Arslanoğlu A et al. Doctors' and intern doctors' knowledge about patients' ionizing radiation exposure doses during common radiological examinations. Diagnostic and Interventional Radiology, 2007, 13:53-55.

7. Myles $\mathrm{P}$ et al. Diagnostic radiation procedures and risk of prostate cancer. British Journal of Cancer, 2008, 98:1852-1856.

8. Shiralkar S et al. Doctors' knowledge of radiation exposure: questionnaire study. British Medical Journal, 2003, 327:371372.

9. Rice HE et al.; APSA Education Committee. Peer assessment of pediatric surgeons for potential risks of radiation exposure from computed tomography scans. Journal of Pediatric Surgery, 2007, 42:1157-1164.

10. Quinn AD et al. Radiation protection awareness in non-radiologists. British Journal of Radiology, 1997, 70:102-106.

11. Jacob K, Vivian G, Steel JR. X-ray dose training: are we exposed to enough? Clinical Radiology, 2004, 59:928-934.
12. Lee $\mathrm{Cl}$ et al. Diagnostic CT scans: assessment of patient, physician, and radiologist awareness of radiation dose and possible risks. Radiology, 2004, 231:393-398.

13. Thomas KE et al. Assessment of radiation dose awareness among pediatricians. Pediatric Radiology, 2006, 36:823-832.

14. Heyer CM et al. [Awareness of radiation exposure of thoracic CT scans and conventional radiographs: what do non-radiologists know?]. Einschätzung der Strahlenbelastung radiolob gischer Thorax-Verfahren: Was ist Nichtradiologen bekannt? Fortschritte auf dem Gebiet der Röntgenstrahlen und der bildgebenden Verfahren, 2007, 179:261-267.

15. Soye JA, Paterson A. A survey of awareness of radiation dose among health professionals in Northern Ireland. British Journal of Radiology, 2008, 81:725-729.

16. Correia MJ et al. Lack of radiological awareness among physicians working in a tertiary-care cardiological centre. International Journal of Cardiology, 2005, 103:307-311.

17. Alotaibi M, Saeed R. Radiology nurses' awareness of radiation. Journal of Radiology Nursing, 2006, 25:7-12.

18. Renston JP, Connors AF Jr, DiMarco AF. Survey of physicians attitudes about risks and benefits of chest computed tomography. Southern Medical Journal, 1996, 89:1067-1073.

19. Lopez KA et al. Clinical usefulness and safety of routine intraoperative angiography for patients and personnel. Neurosurgery, 2007, 61:724-730.

20. Lautin EM, Novick MK, Jean-Baptiste R. Tailored CT: primum non nocere. British Journal of Radiology, 2008, 81:442-443.

21. International Commission on Radiological Protection. Recommendations of the ICRP: ICRP Publication 103. Annals of the ICRP, 2007, 37(2-4). 